\title{
Analysis of Ear, Nose and Throat Foreign Bodies in Dhulikhel Hospital
}

\author{
Shrestha I, Shrestha BL, Amatya RCM
}

Department of ENT + Head \& Neck surgery

Dhulikhel Hospital, Kathmandu University School of Medical Sciences, Dhulikhel Nepall

Corresponding Author

Inku Shrestha

Department of ENT + Head \& Neck surgery

DhuLikhel Hospital

Kathmandu University School of Medical Sciences Dhulikhel, Nepal

Email: shresthainku@gmail.com

\section{Citation}

Shrestha I, Shrestha BL, Amatya RCM. Analysis of Ear, Nose and Throat Foreign Bodies in Dhulikhel Hospital. Kathmandu Univ Med J 2012;38(2):4-8.

\section{ABSTRACT \\ Background}

Foreign body in ear nose and throat are commonly encountered by otolaryngologists, pediatricians and primary care physicians.

\section{Objective}

The aim of this study is to analyze different types of foreign bodies and sociodemographic correlates of self-inflicted foreign body insertion in ear-nose-throat.

\section{Method}

This was a two year hospital based cross sectional descriptive study performed in the Department of ear nose and throat (ENT), Dhulikhel Hospital - Kathmandu University from June 2009 to June 2011 after verification from the Institutional Review Committee. Using a predesigned questionnaire, socio-demographic data was collected prospectively by examining clinically all patients attending with foreign body and interviewing the caregivers of pediatric patients after removal of foreign body. The data collected from 312 patients was entered and analyzed by using descriptive and analytical statistical methods using SPSS version 16.0.

\section{Results}

The mean age was 21.26 years with majority between $0-10$ years (50.6\%). Male predominance was noted (58.97\%). Most patients or caregivers were illiterate (35.1\%) or literacy up to primary level(21.12\%).Foreign body of the ear was found to be most frequent ( $47.4 \%)$ and mostly they were non-living (96.1\%). Most patients presented late $(80 \%)$ and had history of prior attempted removal (67\%). Pearsons chi square test between education level and duration of time was significant ( $p$ value- 0.0000). One way ANOVA test between type of foreign body and age was significant ( $p$ value- 0.001 ).

\section{Conclusion}

Foreign bodies are common in adult and pediatric ear, nose and throat. They can potentially be associated with significant complications if not taken care of immediately.

\section{KEY WORDS}

Foreign body, inorganic, living, non- living, organic

\section{INTRODUCTION}

The different types of foreign bodies (FB) are classified as living and non living. The non living ones are categorized into organic and inorganic. Foreign body in the ear nose and throat is a common problem encountered by otolaryngologists, pediatricians and primary care physicians. They account to about $11 \%$ of cases of emergencies in Otorhinolaryngology. ${ }^{1,2}$

Foreign bodies were most common in younger children less than five years of age..$^{1-4}$ Certain factors are responsible leading to foreign body insertion in ear, nose and throat like curiosity or desire to explore orifices especially by 
children. ${ }^{1,2,5,6}$ This occurs due to easy availability of the objects and absence of watchful caregivers. Other factorials are imitation, boredom, fun making, mental retardation, insanity and attention deficit hyperactivity disorder. ${ }^{1,7}$

In the developed world, there are established and continually evolving protocols for the management whereas in the developing countries such protocols do not exist. Many people resort to self-treatment, without contacting professional health care workers to save time, money, thinking it to be a minor ailment, lack of otolaryngologists and thus lead to complications. ${ }^{1,8-10}$

The different types of foreign bodies are classified as living and non-living. Amongst the non-living ones are organic and inorganic. Removal of foreign bodies requires good anatomical knowledge along with certain skills and techniques depending on its location.

The aim of this study is to analyze different types of foreign bodies encountered and socio-demographic correlates of self-inflicted foreign body insertion in ear-nose-throat.

\section{METHODS}

This hospital based cross sectional study was performed from June 2009 to June 2011performed in the Department of ENT-HNS, Dhulikhel Hospital-Kathmandu University Hospital, after approval by Institutional Review committee. Data was collected using predesigned questionnaire while taking history and clinical examination and also interviewing the caregiver of the paediatric patients, which included age, sex, address, level of education, site of lodgment, type of FB, duration, and attempt of removal. Patients with any types of foreign bodies and patients of all ages were were included in the study. The data collected from 312 patients were entered and analyzed by using SPSS 16.0 version. Descriptive and inferential tests were used for statistical calculations.

\section{RESULTS}

Three hundred and twelve cases of foreign bodies in ENT were included in the study. The mean age of the study subjects was $17.19 \pm 18.19$ years, with minimum age of one year and maximum of 80 years. Majority of cases were children of age group of $0-10$ years $(50.6 \%)$, followed by 11 20 years (15.3\%). Male predominance was noted (58.9\%). Majority of cases were from Kavre district (61\%) followed by Sindhupalchok, Bhaktapur, Ramechhap and Sindhuli. Most patients, as well as parents of children were either illiterate or with literacy up to primary level. (Table 1)

Foreign body of the ear was found to highest with 148 cases $(47.4 \%)$ followed by throat 81 (26.0\%), nose 73 $(23.4 \%)$, oesophagus nine $(2.95)$ and foreign body in the airway bronchus was lowest with only one case $(0.3 \%)$.

Most of foreign bodies were non-living 300 (96.16\%)
Table 1. Socio-demographic findings ( $\mathbf{n = 3 1 2 ) .}$

\begin{tabular}{llc|}
\hline Age distribution( in years) & & \\
\hline Age in years & Number & $(\%)$ \\
\hline$<10$ & 158 & 50.64 \\
\hline $11-20$ & 48 & 15.38 \\
\hline $21-30$ & 33 & 10.6 \\
\hline $31-40$ & 29 & 9.2 \\
\hline $41-50$ & 28 & 8.97 \\
\hline $51-60$ & 4 & 1.28 \\
\hline$>60$ & 12 & 3.84 \\
\hline Sex distribution & & \\
\hline Male & 184 & 58.97 \\
\hline Female & 128 & 41.02 \\
\hline Level of education of patients / caregivers & \\
\hline Illiterate & 112 & 35.89 \\
\hline Primary & 66 & 21.15 \\
\hline Lower secondary & 30 & 9.61 \\
\hline secondary & 50 & 16.02 \\
\hline Higher secondary & 48 & 15.38 \\
\hline Bachelors & 6 & 1.92 \\
\hline & & \\
\hline
\end{tabular}

whereas living insects were seen in 12 cases (3.84\%). Among the non-living ones there were $152(48.7 \%)$ inorganic and 148 (47.4\%) organic substances. (Table 2)

Table 2. Distribution according to type of foreign body ( $n=312)$.

\begin{tabular}{|c|c|}
\hline Type of foreign body & Number(\%) \\
\hline Living & $12(3.84)$ \\
\hline -Insect & $12(3.84)$ \\
\hline Non-living : Organic & $148(47.43)$ \\
\hline -Bone ( fish, chicken, mutton) & $52(16.66)$ \\
\hline $\begin{array}{l}\text {-Maize, Rice Grain, Bean, } \\
\text { Pea,seed }\end{array}$ & 84 \\
\hline - Feather of birds & $12(3.84)$ \\
\hline Non-living : Inorganic & $152(48.71)$ \\
\hline -Stone & $68(21.79)$ \\
\hline -Eraser/pensil or pen tip & $54(17.3)$ \\
\hline - Cotton balls & $16(5.12)$ \\
\hline - Paper & $10(3.2)$ \\
\hline -Marble & $4(1.28)$ \\
\hline
\end{tabular}

About 63 patients (20\%) came within one day of lodgement, 162 (52\%) between 1-3 days and 47(15\%) between 3-7 days. There were 40 patients (13\%) cases who presented later than 7 days. (Fig 1)

There was a history of previous attempt of removal or primary treatment taken before presentation in 210 cases (67\%).

Multinomial logistic regression test between completed level of education and time interval between foreign body 


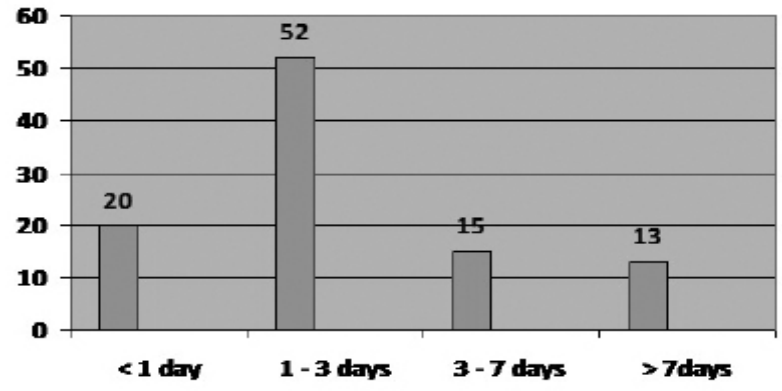

Figure 1. Duration on lodgement at presentation in percentage $(n=312)$.

lodgment and final presentation was highly significant ( $p$ value- 0.0000$)$. The people with higher education level comes earlier for medical help. One way ANOVA test suggests that type of foreign body was highly significant according to age ( $p$ value- 0.001 ) because live insects enter the wider canal of predisposed adults whereas, children put small objects in the orifices themselves due to curiosity, imitation, easy accessibility, boredom, funmaking or attention deficit hyperactivity disorder. (Fig 2)

\section{DISCUSSION}

Foreign bodies in ENT account for $11 \%$ of emergency cases in otorhinolaryngology. ${ }^{1,2}$ The male predominance and age structure as revealed by the present study were supported by other studies..$^{1-4,11,12}$ The anal and phallic Oedipal stages following the oral stage of development as described by Sigmond Freud not only predispose a child for anal manipulations, but also give him pleasure of manipulating the various orifices including the ear, nose and throat. ${ }^{3,12}$

Insertion of foreign bodies by the little children may be precipitated by boredom, frustration and also mimicking the unhealthy habits of ear and nose picking by adults. Literacy rate seems to be an important factor for avoiding FB insertion or any delay to seek treatment. ${ }^{1}$ This study has also supported that completed level of education and duration of time at presentation is highly significant at 0.01 level according to Multinominal logistic regression test. However, Despres $\mathrm{N}$, et al commented that in spite of excellent education the insertion of foreign body in children, cannot be eliminated completely but there is a scope of alerting the common people and the villagers regarding the complications of foreign body in ENT and care. $^{13}$

Patients or parents of children may attempt removal by themselves or by the help of nearby medical personnel.

There was a preponderance of foreign body of ear (47\%), as evident by present study followed by throat foreign body $(25 \%)$ and nose $(23 \%)$. This was contrary to other study where nose FB was preponderant. ${ }^{1}$ Cases with predisposing ear problems like itching, pain, heaviness , discomfort, hearing impairment may compel a person both children and adults to probe the ear with some object

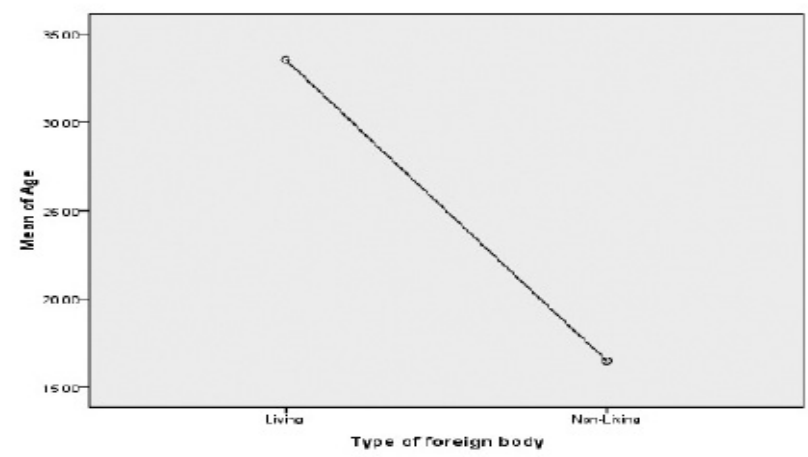

Figure 2. One way ANOVA test between age and type of foreign body.

leading to foreign body impaction as well as injury. ${ }^{1,3}$

About location, the most frequent anatomical site of FB encounter in ear is bony part of external auditory canal. In nose are between the inferior turbinate and the septum and anteriorly to middle concha. Insects usually enter the external auditory canal when it gets partially embedded in the wax and creates abrasions during its struggle. Its movement produces itching thus tempting the patient to scratch and produce further abrasions. This maneuver may even result in tympanic membrane perforation. Owing to phototropism every attempt must be made to allow a living insect to crawl out by throwing a bright beam of light into the external auditory canal or anterior nares before manipulation. Another method used by most authors is to drown the insects especially arthropods in either mineral oil, lignocaine solution or betadine. ${ }^{3,14}$ We have also used turpentine oil soaked in cotton pledgets in anterior nares or external auditory canal in cases of maggots to suffocate the maggots which causes them to crawl outside.

There were three cases of Leech as foreign body in the nose and all cases gave history of drinking water from local stone taps, or streams. That is probably due to leeches found around wet and damp areas. They were removed by suctioning and forceps. This study also shows a significant correlation between type of foreign body (living / nonliving ) according to age.

Three cases were of myiasis, two in the nasal cavity and one in the ear. Both nasal myiasis were atrophic rhinitis associated, whereas the exact cause is still unknown in case of aural myiasis. He may have had otitis externa along with unhygienic conditions leading to attraction of the flies and lying of eggs leading to myiasis.

Methods used to remove foreign bodies of ear were suctioning, syringing, forceps removal, hooks and probes. For nasal foreign bodies methods used for evacuation were suctioning, forceps, hooks and probes. Foreign body throat was removed with forceps.

Flexible endoscope guided removal was done in foreign body oesophagus which was removed with flexible endoscopy in view of complications related to rigid oesophagoscopy and kept it as second line in case flexible 
failed to retrieve the foreign body. ${ }^{15-17}$

The presence of otorrhoea with FB (other than aural myiasis) also suggests perforation of tympanic membrane and syringing should be avoided in such conditions. Syringing should also be avoided in cases with history of prior instrumentation fearing otitis externa.

Alternate method for foreign body extraction is cyanoacrylite glue, which was not practiced in our patients. ${ }^{3,12,18}$

In cases of anxious patients, crying children or inexperienced hands there is a chance of the foreign body getting pushed more inside and injuring surrounding tissues or entering the airway thus causing airway emergency as in cases of nasal foreign body. In some of our young patients $<10$ years we have removed the $\mathrm{FB}$ under intravenous dissociate anesthesia (Ketamine) which relaxes the child for a short time and helps to make controlled extraction under magnification possible. ${ }^{3}$

None of our aural FB showed any migration to surrounding soft tissues. ${ }^{19}$

There is seldom any need for routine or special investigations in localizing a foreign body. ${ }^{3}$

In their studies Mukherjee A et al and ljaduala GTA et al found similar findings like the present study that most foreign body insertion cases belonged to lower socioeconomic condition. ${ }^{1,20}$ Other observers opined irritation caused by local pathology as an important predisposing factor for foreign body insertion into ear and nose which also seemed concordant with the present study. ${ }^{3}$ Repeat foreign body insertion was found to be significantly more in the nasal cavity with might be due to its easy accessibility.

This study recommends that education should be encouraged in the people, especially the care givers of children. Underlying predisposing conditions should be treated. People should not insert anything in the orifices unless indicated which will also avoid copying behavior among children. It also highlights the importance of public health awareness regarding foreign bodies' insertion and its related complications.

\section{CONCLUSION}

Foreign bodies are common in adult and pediatric ear, nose and throat. The nature of foreign body and site of lodgment may differ in different ages and between different places. They can be of different types from living to non-living and people usually have history of attempted removal before they land in the department of ENT. They can potentially be associated with significant complications if not taken care of immediately and most of times require skillful removal.

\section{ACKNOWLEDGEMENT}

We would like to thank Mr Seshananda Sanjel and Mr Kishore Khanal from Department of Community Medicine for their help during statistical analysis of this study. The authors would also like to thank Dr Indranil Ghosh, Mr Mahendra Khadka and Mr Deepak Karki for their contributions in collection of data and helping in procedures.

\section{REFERENCES}

1. Mukherjee A, Haldar D, Dutta S, Dutta M, Saha J, Sinha R. Ear, nose and throat foreign bodies in children: A search for socio-demographic correlates. International Journal of Pediatric Otorhinolaryngology. 2011;75(4):510-2.

2. Ribeiro da Silva BS, Souza LO, Camera MG, Tamiso AGB, Castanheira VR. Foreign bodies in otorhinolaryngology: a study of 128 cases. Int. Arch. Otorhinolaryngol. 2009;13(4):394-9.

3. Mishra A, Shukla GK, Bhatia N. Aural Foreign bodies. Indian J of pediatrics. 2000;67(4):267-269.

4. Afolabi O, Alabi B, Segun-Busari S, Dunmade A, Ologe F. Paediatric aural foreign bodies: a challenge to care givers. The Internet Journal of Otorhinolaryngology 2009;11(1).

5. Stuart F, Gabor D, Kerth T. Foreign body of the external auditory canal. Emerg Med Clin N Am. 1987;5:183-9.

6. Okafor BC. Trauma to ear including foreign bodies. Niger Med J. 1983;13:81-86.

7. Perera H, Fernando S, Yasawardena A, Karunaratne I. Prevalence of attention deficit hyperactivity disorder (ADHD) in children presenting with self-inserted nasal and aural foreign bodies. Int J Paediatr Otorhinolaryngol. 2009;73(10):1362-4.

8. Afolabi AO. Factors influencing the pattern of self medication in an adult Nigerian population. Ann Afr Med. 2008;7(3):120-7.

9. Ibrahim M.I. Treating one's own ailment. World Health Forum. 1996;17:409-10.

10. Sandler G. South Africa: self-medication. Lancet. 1990;335:1149.

11. Bloom DC. Plastic laryngeal foreign bodies in children: A diagnostic challenge. International Journal of Pediatric Otorhinolaryngology. 2005;69:657-2

12. Carney AS. Foreign bodies in the ear and the aerodigestive tract in children. In: Gleeson MJ, ed. Scott Brown's otolaryngology. 7th ed. Canada: Hodder Arnold Publishers; 2008. 1184-93.

13. Despres N, Lapointe A, Quintal MC, Arcand P, Giguere C, Abela A. 3-Year impact of a provincial choking prevention program. J Otolaryngol. 2006;35(4):216-1.

14. Ryan C, Ghosh A, Smit D, Boyd WB, O'Leary S. Adult Aural Foreign Bodies. The Inter-net Journal of Otorhinolaryngology 2006;4(2).

15. Akinkunmi M, Olubi O. Beef Meat Oesophageal Foreign Body Impaction In An Infant. The Internet Journal of Health 2010;11(2). Available from http://www.ispub.com:80/journal/the-internetjournal-of-health/volume-11-number-2/beef-meat-oesophagealforeign-body-impaction-in-an-infant.html

16. Pokharel R, Adhikari P, Bhusal CL, Guragain RP. Oesophageal foreign bodies in children. $J$ Nepal Med Assoc. 2008; 47:186-8.

17. Gmeiner D, von Rahden BH, Meco C, Hutter J, Oberascher G, Stein HJ. Flexible versus rigid endoscopy for treatment of foreign body impaction in the esophagus. Surg Endosc. 2007;21:2026-9.

18. Pride H. Schwab R. A new technique for removing foreign bodies of external auditary canal. Pediatric Emergency care. 1989;5(2):135-6. 
19. Viswanatha B, Dutta RK, Anilkunar R, Sumatha D. Migration of a foreign body from post aural area to the external ear canal. The Internet Journal of Otorhinolaryngology. 2009;10(2).
20. Ijaduola GTA, Okeowo PA. Foreign body in the ear and its importance: the Nigerian experience. J Trop Paediatr. 1986;32(1):4-6. 